\title{
ИСПОЛЬЗОВАНИЕ САХАРНО-КИСЛОТНОГО ИНДЕКСА ДЛЯ ОЦЕНКИ КАЧЕСТВА ПЛОДОВ ТОМАТОВ
}

\author{
V. A. Machulkina, T. A. Sannikov, \\ A. V. Gulin, N. I. Antipenko
}

\section{USING THE SUGAR AND ACID INDEX FOR THE ASSESSMENT OF THE QUALITY OF TOMATOES FRUITS}

\begin{abstract}
Мачулкина Вера Александровна - д-р с.-х. наук, вед. науч. сотр. отдела агротехнологий и мелиораций Всероссийского НИИ орошаемого овощеводства и бахчеводства - филиала Прикаспийского аграрного федерального научного центра РАН, Астраханская обл., г. Камызяк.

E-mail: vniiob@mail.ru
\end{abstract}

Санникова Татьяна Александровна - д-р с.-х. наук, вед. науч. сотр. отдела агротехнологий и мелиораций Всероссийского НИИ орошаемого овощеводства и бахчеводства - филиала Прикаспийского аграрного федерального научного центра РАН, Астраханская обл., г. Камызяк.

E-mail: tani.1957@bk.ru

Гулин Александр Владимирович - канд. с.-х. наук, вед. науч. сотр. отдела селекции и семеноводства, директор Всероссийского НИИ орошаемого овощеводства и бахчеводства - филиала Прикаспийского аграрного федерального научного центра РАН, Астраханская обл., г. Камызяк.

E-mail: vniiob@mail.ru

Антипенко Наталия Ивановна - канд. с.-х. наук, ст. науч. сотр. отдела агротехнологий и мелиораций Всероссийского НИИ орошаемого овощеводства и бахчеводства - филиала Прикаспийского аграрного федерального научного центра РАН, Астраханская обл., г. Камызяк.

E-mail: vniiob@mail.ru

Цель исследования - изучить и выявить наиболее перспективные сорта томатов селекции ВНИИООБ по вкусовым качествам на основании сахарно-кислотного индекса и биохимическим показателям. Предоставлены результаты изменения качественных показателей плодов томатов. Исследование проводили на сортах Лучистый, Супергол, Бульдог, Оранжевый салатный, Форвард, Гигантелла, Acm-
Machulkina Vera Alexandrovna - Dr. Agr. Sci., Leading Staff Scientist, Department of Agrotechnologies and Melioration, All-Russia Research Institute of Irrigated Vegetable and Melon Growing - Branch of Caspian Federal Agrarian Research Center RAS, Astrakhan Region, Kamyzyak. E-mail: vniiob@mail.ru

Sannikova Tatyana Alexandrovna - Dr. Agr. Sci., Leading Staff Scientist, Department of Agrotechnologies and Melioration, All-Russia Research Institute of Irrigated Vegetable and Melon Growing - Branch of Caspian Federal Agrarian Research Center RAS, Astrakhan Region, Kamyzyak.

E-mail: tani.1957@bk.ru

Gulin Alexander Vladimirovich - Cand. Agr. Sci., Leading Staff Scientist, Department of Selection and Seed Farming, Director, All-Russia Research Institute of Irrigated Vegetable and Melon Growing - Branch of Caspian Federal Agrarian Research Center RAS, Astrakhan Region, Kamyzyak.

E-mail: vniiob@mail.ru

Antipenko Natalia Ivanovna - Cand. Agr. Sci., Senior Staff Scientist, Department of Agrotechnologies and Melioration, All-Russia Research Institute of Irrigated Vegetable and Melon Growing Branch of Caspian Federal Agrarian Research Center RAS, Astrakhan Region, Kamyzyak.

E-mail: vniiob@mail.ru

раханский (контроль) селекции ВНИИООБ фолиала ФГБНУ «ПАФНЦ РАН» Астраханской области. Изучали изменения содержания основных химических веществ в свежих плодах томатов и после кратковременного хранения (10 сут) в естественных условиях хранилища. Биохимические параметры оценки качества плодов проводили по содержанию сухого вещества, суммы сахаров, кислотности, аскорбиновой 
кислоты, нитратов. По результатам исследования выявлено, что наиболее высокое отношение сахар/кислота как до хранения, так и после отмечено у сортов Супергол, Бульдог и Оранжевый салатный и находилось в пределах 10,2-12,2 единицы, что в 1,7 раза выше нормативного показателя (7 единии). Более низкие вкусовые качества были у сортов Астраханский (контроль) - 8,8 и Форвард - 8,9. Дегустационная оценка изучаемых сортов томата составила 4,1-4,9 балла до хранения и 3,9-4,5 балла после кратковременного хранения. По содержанию аскорбиновой кислоты сорта Супергол, Бульдог и Оранжевый салатный превышали в 1,3-2,1 раза другие изучаемые сорта. По накоплению нитратов вышеуказанные сорта соответствовали экологически чистому продукту питания, так как их содержание было ниже в 4,1-7,5 раза предельно допустимой концентрации (150 мг/кг сырого вещества). Следовательно, сорта селекции ВНИИООБ по сахарно-кислотному индексу и биохимическим показателям отвечают высоким вкусовым качествам и экологически чистому продукту питания.

Ключевые слова: томаты, сорт, сахарнокислотный индекс, качество плодов, хранение.

The purpose of the study was to study and identify the most promising tomato varieties of selection of the All-Russia Research Institute of Irrigated Vegetable and Melon Growing collection in terms of taste based on sugar-acid index and bio-chemical parameters. The results of the change of the quality indicators of fruits of tomatoes were reported. The research was conducted on the varieties Luchisty, Supergol, the Bulldog, Oranzhevy salatny, Forward, Gigantella, Astrakhansky (control) of selection of AllRussia Research Institute of Irrigated Vegetable and Melon Growing - Branch of Caspian Federal Agrarian Research Center RAS, Astrakhan Region. The changes of the content of the main chemicals in fresh fruits of tomatoes and after short-term storage (10 days) under natural conditions of storage were studied. Biochemical parameters estimates of the quality of fruits were carried out according to the content of solid, the sum of sugars, acidities, ascorbic acid, nitrates. By the results of the research it was found out that the highest relation sugar/acid both before storage, and after it was noted in the varieties Supergol, Bulldog, Oranzhevy salatny, and was in the limits of 10.2-12.2 units, i.e. 1.7 times higher than the standard indicator (7 units). Lower tastes varieties had Astrakhan (control) -8.8 and Forward - 8.9. Tasting assessment of the studied tomato varieties made 4.1-4.9 points before storage and 3.9-4.5 points after short-term storage. According to the content of ascorbic acid of the varieties Supergol, Bulldog and Oranzhevy salat exceeded other studied varieties 1.3-2.1 times. On the accumulation of nitrates the above varieties corresponded to environmentally friendly food product as their content was 4.1-7.5 times lower than maximum permissible concentration $(150 \mathrm{mg} / \mathrm{kg}$ of crude substance). Therefore, the varieties of selection of AllRussia Research Institute of Irrigated Vegetable and Melon Growing in the sugar acid index and biochemical indicators meet the requirements for high taste and an environmentally friendly food product.

Keywords: tomatoes, variety, sugar and acid index, fruit quality, storage.

Введение. Улучшение качества продукции является одним из основных путей интенсификации производства. Известно, что качество потребляемой овощной продукции зависит от культуры, ее способности накапливать как полезные, так и вредные вещества. Так как почти три четверти товаров народного потребления производится из продуктов отрасли сельского хозяйства, проблема качества имеет большое значение для реализации продовольственной программы [1 - 3]. В последние годы плодоовощная промышленность достигла больших успехов в увеличении выпускаемой продукции и способна полностью обеспечить население отечественной экологически чистой продукцией [4].

Овощи, в том числе томаты, непременная составная часть питания человека. Врачи рекомендуют ежедневно потреблять 350-400 граммов овощей в свежем, консервированном или замороженном виде. Поэтому государство уделяет большое внимание инновационному развитию сельскохозяйственного производства, повышению его конкурентоспособности [5]. 
Астраханская область является одной из ведущих производителей томатов, выращиваемых в открытом грунте. Несмотря на складывающуюся положительную динамику роста объемов производства продукции, остается не решенным ряд важных проблем - дальнейшее увеличение производства овощей, внедрение адаптированных высокоурожайных отечественных сортов томатов, лежкоспособных, транспортабельных, с высокими вкусовыми качествами [6].

Большую часть сухих веществ в плодах томатов составляют углеводы, основную из них - растворимые сахара. Вкус плодов определяется показателем отношения сахара к кислоте. Доказано, что этот показатель изменяется в зависимости от почвенно-климатических условий, агротехники возделывания и сортовых особенностей культуры, степени зрелости плода [4-6]. Данные по соотношению сахара к кислоте, полученные исследователями, значительно отличаются в зависимости от сорта, климатических условий. Так, в работах ряда исследователей отмечается, что плоды томатов, выращенных в неблагоприятных условиях, содержали больше кислот и меньше сахаров, а при выращивании в оптимальных условиях накапливали больше сахаров. Еще в 1961 г. А.И. Ермаков и В.В. Арасимович в своих работах отметили закономерность увеличения сахаров в плодах томатов при выращивании их с севера на юг [1]. Поэтому отношение сахара к кислоте широко используется как показатель качества плодов. Ценятся плоды с высоким показателем сахара к кислоте $[1,6]$.

Цель исследования: изучить и выявить наиболее перспективные сорта томатов селекции ВНИИООБ по вкусовым качествам на основании сахарно-кислотного индекса и биохимическим показателям.

Задачи исследования: оценить вкусовые качества плодов томатов селекции ВНИИООБ по отношению сахара к кислоте, определить изменение органолептических и биохимических показателей плодов до и после хранения.

Методика исследования. Исследование проводили на плодах томатов, выращенных на опытном участке, оборудованном закрытым дренажем и представленном аллювиально- луговыми почвами, сформированными в дельте реки Волги на суглинистых аллювиальных отложениях, подстилаемых на глубине 50-130 см песком и супесями. Наименьшая влагоемкость в слое 0-30 см - 27,9 \% НВ. Содержание гумуса в почве 0-20 см - 1,7-4,0 \%, гидролизуемого азота - 80-140 мг/кг, подвижного фоссфора - 2845 мг/кг, обменного калия - 250-400 мг/кг почвы. В исследовании использовали сорта селекции ВНИИООБ: Лучистый, Супергол, Бульдог, Оранжевый салатный, Форвард, Гигантелла, Астраханский (контроль).

Опыты закладывались в 4-кратной повторности. За повторность принималась одна единица упаковки массой 5 кг. На кратковременное хранение плоды томатов закладывались в хранилище с естественно сложившимися условиями (температура $+20-22{ }^{\circ} \mathrm{C}$, относительная влажность воздуха 65-70 \%). В плодах томатов определяли сухое вещество, сумму сахаров, кислотность, аскорбиновую кислоту и нитраты как до хранения, так и после хранения, которые определялись химической лабораторией института согласно действующим методикам.

Сахарно-кислотный индекс плодов определяли отношением сахара к кислоте. Дегустационная комиссия оценивала плоды томатов по внешнему виду, вкусу по пятибалльной шкале.

Учет сахарно-кислотного индекса и дегустационной оценки плодов проводили до закладки и после краткосрочного хранения в естественно сложившихся условиях хранилища.

Результаты исследования. Как отмечалось выше, отношение сахара к кислоте - это показатель качества плодов, и чем он выше, тем вкуснее продукт. По нормативным данным этот показатель должен быть не ниже 7 единиц. Установлено, что все изучаемые сорта имели различный сахарно-кислотный индекс, но превышали нормативный показатель. Лучшими были сорта Супергол, Бульдог и Оранжевый салатный, их индекс составил 12,0; 12,2 и 11,9 соответственно, что в 1,4 раза выше контроля сорта Астраханский. Сорт Форвард по данному показателю был на уровне контроля, сорта Лучистый и Гигантелла незначительно превышали контроль (табл.). 


\section{Влияние сорта на вкусовые качества плодов томатов}

\begin{tabular}{|c|c|c|c|c|c|c|c|}
\hline \multirow[b]{2}{*}{ Сорт } & \multicolumn{7}{|c|}{ Показатель } \\
\hline & 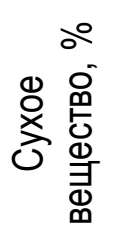 & 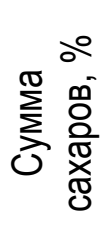 & 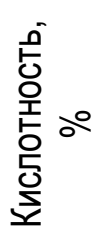 & 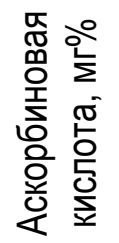 & 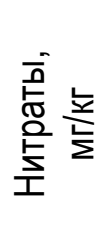 & 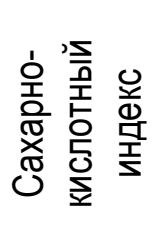 & 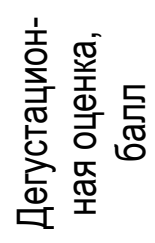 \\
\hline \multicolumn{8}{|c|}{ До хранения } \\
\hline $\begin{array}{l}\text { Астраханский } \\
\text { (контроль) }\end{array}$ & 6,82 & 3,61 & 0,41 & 11,0 & 33,2 & 8,8 & 4,5 \\
\hline Лучистый & 6,94 & 3,46 & 0,32 & 11,88 & 32,1 & 10,8 & 4,4 \\
\hline Супергол & 5,28 & 3,59 & 0,30 & 12,83 & 23,8 & 12,0 & 4,5 \\
\hline Бульдог & 5,64 & 3,89 & 0,32 & 18,91 & 32,2 & 12,2 & 4,9 \\
\hline $\begin{array}{l}\text { Оранжевый } \\
\text { салатный }\end{array}$ & 5,58 & 3,46 & 0,29 & 13,13 & 28,9 & 11,9 & 4,7 \\
\hline Форвард & 5,20 & 3,29 & 0,37 & 9,36 & 35,2 & 8,9 & 4,5 \\
\hline Гигантелла & 5,56 & 3,30 & 0,35 & 11,08 & 37,0 & 9,6 & 4,1 \\
\hline \multicolumn{8}{|c|}{ После 10 суток хранения в естественных условиях хранилища } \\
\hline $\begin{array}{l}\text { Астраханский } \\
\text { (контроль) }\end{array}$ & 7,03 & 3,43 & 0,43 & 10,43 & 28,6 & 8,0 & 4,3 \\
\hline Лучистый & 6,29 & 3,27 & 0,35 & 11,54 & 27,4 & 9,1 & 4,2 \\
\hline Супергол & 5,43 & 3,98 & 0,33 & 11,68 & 20,1 & 10,2 & 4,2 \\
\hline Бульдог & 5,84 & 3,61 & 0,35 & 18,68 & 29,7 & 10,3 & 4,5 \\
\hline $\begin{array}{l}\text { Оранжевый } \\
\text { салатный }\end{array}$ & 5,73 & 3,23 & 0,31 & 12,94 & 25,4 & 10,4 & 4,4 \\
\hline Форвард & 5,37 & 3,19 & 0,39 & 8,88 & 30,1 & 8,2 & 4,1 \\
\hline Гигантелла & 5,73 & 3,22 & 0,33 & 10,57 & 33,6 & 9,7 & 3,9 \\
\hline
\end{tabular}

В соответствии с данными таблицы, содержание сухого вещества после 10 суток хранения незначительно увеличилось за счет испарения влаги в процессе дыхания плодов. При этом отмечено уменьшение суммы сахаров и увеличение кислотности плодов, что привело к снижению сахарно-кислотного индекса в 1,1-1,2 раза.

Изменение аскорбиновой кислоты в процессе хранения связано с биологическими особенностями плодов томатов. Так как на хранение закладывали зрелые плоды, когда процесс созревания уже закончился и началась мацерация тканей, то в результате даже непродолжительного хранения произошло снижение аскорбиновой кислоты на 0,48-1,15 мг\%.

Выявлено, что при предельно допустимой концентрации нитратов в плодах томатов 150 мг/кг сырого вещества их количество колебалось от 28,9 до 37,0 мг/кг до хранения и от 20,1 до 33,6 мг/кг после 10-суточного хранения в зависимости от сорта.
По данным таблицы, сорта Бульдог и Оранжевый салатный на 0,1-0,8 балла были выше по результатам дегустационной оценки в сравнении с другими изучаемыми сортами как до хранения, так и после. Показатели содержания сухого вещества, аскорбиновой кислоты и нитратов в плодах изучаемых сортов томата соответствовали высоковитаминному продукту питания по накоплению витамина С.

Вывод. Таким образом, сахарно-кислотный индекс зависит от сорта и аккумуляции в плодах сахаров и кислот. Наилучшими по данному показателю были сорта Супергол, Бульдог и Оранжевый салатный, остальные сорта им уступали, но сахарно-кислотный индекс у них был в 1,1-1,7 раза больше по сравнению с рекомендуемым показателем (7). Следовательно, все изучаемые сорта имеют высокие вкусовые качества, что подтверждено дегустационной оценкой, составляющей 3,9-4,9 балла. 


\section{Литература}

1. Ермакова А.И., Арасимович В.В. Биохимия овощных культур. Л., 1961. С. 57.

2. Санникова Т.А. и др. Целевая оценка овощной продукции: мат-лы междунар. науч.практ. конф. // Ресурсосберегающие технологии возделывания сельскохозяйственных культур в орошаемых агрофитоценозах. Астрахань, 2011. С. 89-92.

3. Санникова Т.А., Мачулкина В.А. Органолептическая оценка качества овощебахчевой продукции // Наука и образование в жизни современного общества: сб. науч. тр. по мат-лам междунар. науч.-практ. конф. (30 июня 2015 г.). Тамбов, 2015. Т. 3. C. 111-114.

4. Санникова Т.А., Мачулкина В.А., Антипенко Н.И. Качество консервированных томатов в зависимости от сорта и пищевых добавок // Орошаемое земледелие. 2017. № 3. С. 19-20.

5. Мачулкина В.А., Санникова Т.А. Значение сорта при производстве томатного сока // Элементы технологии возделывания сельскохозяйственных культур: сб. тр. междунар. науч.-практ. конф. (28-29 апр. 2016 г., г. Астрахань) / науч. ред. Ш.Б. Байрамбеков. Астрахань, 2016. С. 138-141.

6. Кодратьева И.Ю., Павлов Л.В. Содержание сухих веществ в плодах томатов в зависимости от количественных и качественных признаков // Картофеель и овощи. 2009. № 5. C. 21.

\section{Literatura}

1. Ermakova A.I., Arasimovich V.V. Biohimija ovoshhnyh kul'tur. L., 1961. S. 57.

2. Sannikova T.A. i dr. Celevaja ocenka ovoshhnoj produkcii: mat-ly mezhdunar. nauch.-prakt. konf. // Resursosberegajushhie tehnologii vozdelyvanija sel'skohozjajstvennyh kul'tur v oroshaemyh agrofitocenozah. Astrahan', 2011. S. 89-92.

3. Sannikova T.A., Machulkina V.A. Organolepticheskaja ocenka kachestva ovoshhe-bahchevoj produkcii // Nauka i obrazovanie $v$ zhizni sovremennogo obshhestva: sb. nauch. tr. po mat-lam mezhdunar. nauch.-prakt. konf. (30 ijunja 2015 g.). Tambov, 2015. T. 3. S. 111-114.

4. Sannikova T.A., Machulkina V.A., Antipenko N.I. Kachestvo konservirovannyh tomatov $v$ zavisimosti ot sorta i pishhevyh dobavok /I Oroshaemoe zemledelie. 2017. № 3. S. 19-20.

5. Machulkina V.A., Sannikova T.A. Znachenie sorta pri proizvodstve tomatnogo soka /I Jelementy tehnologii vozdelyvanija sel'skohozjajstvennyh kul'tur: sb. tr. mezhdunar. nauch.prakt. konf. (28-29 apr. 2016 g., g. Astrahan') / nauch. red. Sh.B. Bajrambekov. Astrahan', 2016. S. 138-141.

6. Kodrat'eva I.Ju., Pavlov L.V. Soderzhanie suhih veshhestv $\mathrm{v}$ plodah tomatov $\mathrm{v}$ zavisimosti ot kolichestvennyh i kachestvennyh priznakov // Kartofel' i ovoshhi. 2009. № 5. S. 21. 